TITLE:

The effect of different foundation systems on the fungal flora in the crawl space of a new wooden Japanese house

\author{
$\operatorname{AUTHOR}(S):$
}

Toyoumi, Aya

CITATION:

Toyoumi, Aya. The effect of different foundation systems on the fungal flora in the crawl space of a new wooden Japanese house. Sustainable humanosphere : bulletin of Research Institute for Sustainable Humanosphere Kyoto University 2009, 5: 48-48

ISSUE DATE:

2009-09-10

URL:

http://hdl.handle.net/2433/182142

RIGHT: 


\section{The effect of different foundation systems on the fungal flora in the crawl space of a new wooden Japanese house}

\section{(Laboratory of Innovative Humano-Habitability, RISH, Kyoto University)}

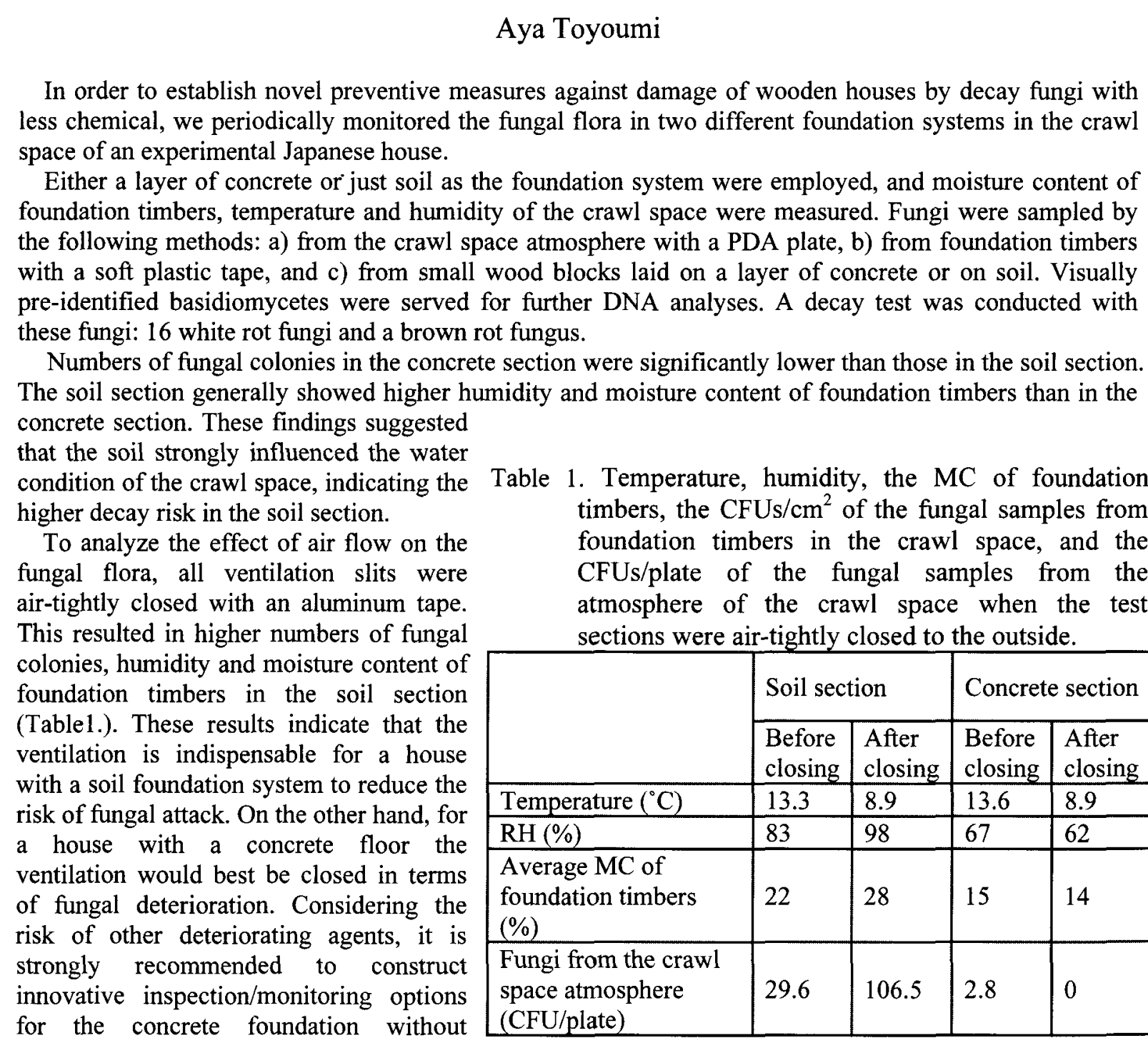
ventilation.

This study clearly indicated the importance of foundation system in wooden houses, and the higher decay risk in the soil floor than in the concrete floor.

\section{Acknowledgements}

The author wishes to thank to Prof. Shuichi Doi (Tsukuba University) and Dr. Sakae Horisawa (Kochi University of Technology) for their kind cooperation. This research was partially supported by the TOSTEM foundation and the Cooperative Study Program of Research Institute for Sustainable Humanosphere, Kyoto University (Wood Composite Hall). 